\title{
Challenges and Research Opportunities of Frequency Control in Low Inertia Systems
}

\author{
Ha Thi Nguyen ${ }^{1,}$, Guangya Yang ${ }^{1}$, Arne Hejde Nielsen ${ }^{1}$, and Peter Hojgaard Jensen ${ }^{2}$ \\ ${ }^{1}$ Center for Electric Power and Energy, Department of Electrical Engineering, Technical University of Denmark, 2800 Kgs. Lyngby, \\ Denmark \\ ${ }^{2}$ Energy Automation, Siemens A/S, 2750 Ballerup, Denmark
}

\begin{abstract}
The dominance of converter-based generation in power systems results in a significant reduction of the number of conventional power plants. The transition introduces major challenges of substituting synchronous generators and their ancillary dynamic control services with converter-interfaced generations whose control and interaction with the grid have not been fully understood. This paper presents challenges and research opportunities of frequency control of such low inertia systems. Challenges of frequency control in converter-based systems and a review of power systems facing the challenges caused by low inertia conditions around the world are first investigated. Then, a summary of the solutions that have been proposed for frequency control in low inertia systems is analysed. The paper will conclude with research opportunities for frequency control in low inertia systems, which require further investigation for converterinterfaced systems.
\end{abstract}

\section{Introduction}

Toward a sustainable energy network, integrating more renewable energy sources into electrical systems has become the main motivation. This aims to replace fossilfuel- and nuclear-based power plants with renewable energy sources. Over the last decade, renewable energy sources have been growing in popularity, generating $22 \%$ of the total global energy consumption in 2013 and have been becoming much more prominent in the world's energy generation. By 2020, China has set an ambitious target of generating over $15 \%$ of its total power from renewable energy with $420 \mathrm{GW}$ from hydro, $200 \mathrm{GW}$ from wind, $50 \mathrm{GW}$ from solar and $30 \mathrm{GW}$ from biomass [1]. The European Union (EU) has made an ambitious agreement to have at least $27 \%$ of whole energy consumption in the EU come from renewable energy sources by 2030 [2]. There are 57 countries having $100 \%$ renewable electricity targets in future [3].

Additionally, more and more HVDC interconnections of the regions or countries have been building based on its advantages to achieve economic benefits for transporting cheaper energy over long distances to the load centres. For instances, in the continental European system, HVDC links namely COBRA cable and Viking link that are connected from Denmark to the Netherlands and England, are under construction and negotiation, respectively $[4,5]$. These interconnections will transport huge amounts of renewable energy from the rich renewable-based countries like Norway and Germany to countries with high consumption or high electricity prices such as England, the Netherlands, and Sweden. Such links are also built in the power systems in Russia, North America, and Asia [6]. As a result, in modern power systems, conventional power plants will be phased out to give a way for converter-interfaced generations like wind, solar, and importing HVDC links. However, such converter-interfaced generations have different characteristics and are often controlled in such a way that they are independent of the system frequency. Firstly, the converter-based generations have low or non-existent inertia, which are usually connected to the grid through power electronic converters. Therefore, they decouple the renewable generator inertia from inertial response, which makes the rate of change of frequency (ROCOF) faster during frequency incidents. Secondly, a decrease in the number of conventional power plants renders primary control and secondary control for frequency control missing, which can lead to the frequency deviation and steady-state frequency error increasing during disturbances. Finally, with the replacement of renewable generators, ancillary services for balancing and transient characteristics of traditional power plants are removed. Consequently, the transition from nuclear- and fossilfuel-based systems to converter-based systems may introduce many challenges for system operation and control because of their different characteristics and control requirements. The most challenging is achieving the frequency stability of these modern systems during disturbances with a low inertia condition.

Many researchers have been investigated the impact of converter-based generation on power system stability and operation. In [7], a review of the research related to system inertia that analyses the challenge in the system

Corresponding author: thangu@elektro.dtu.dk 
operation due to the system inertia reduction. The research proposes storage devices or inertia implementation from converter-interfaced generation as a solution for low inertia systems. Foundations and challenges of low-inertia systems in power system stability, operation, and control are reviewed in [8]. The low inertia effect on power system operation and stability with high converter-connected wind turbine and PV penetration level is analysed in [9]. The study demonstrates that system inertia becomes heterogeneous and frequency dynamics are faster in power systems with a low inertia condition. Comprehensive reviews of the renewable energy impact on the United State's power system operation are presented in $[10,11]$. In [12], different approaches have been proposed for frequency control support in low inertia systems. Consequently, the challenges of low inertia system operation and control have been generally well recognized.

In this paper, challenges of low inertia system on frequency control are analysed based on relevant real-life examples. Then, solutions that have been proposed to address the issue is reviewed. Research opportunities on frequency control of converter-interfaced systems that are foreseeable for low inertia systems are concluded. In particular, the paper focuses on frequency control and transients of low inertia systems.

The remaining part of the paper is organized as follows. Section II presents the challenges of frequency control in low inertia systems. The potential solutions that have been investigated is reviewed in section III. Section IV proposes research opportunities for low inertia system in terms of frequency stability and control.

\section{The challenges of frequency control in low inertia systems}

To well understand the frequency response during frequency events, taking an example with a load increase as shown in Fig. 1, the frequency response can be broken down into different stages as follows: inertial response firstly reacts where the synchronous generators in operation inject the kinetic energy stored in their rotating mass, lasting for around few seconds. This is a physical and inherent characteristic of synchronous generators. Then, if the frequency deviation surpasses a specific value, the primary frequency controller will be immediately activated, which uses the generator governor to return the frequency to acceptable values within $30 \mathrm{~s}$. After around $30 \mathrm{~s}$, there still has a steady-state frequency error; the secondary control will be activated to bring the system frequency back to its nominal value, which needs several minutes to help frequency completely recover. If the secondary control reserve is not sufficient, a tertiary control will be manually applied to adjust the dispatching and unit commitment in order to restore the secondary control reserve and manual eventual congestion.

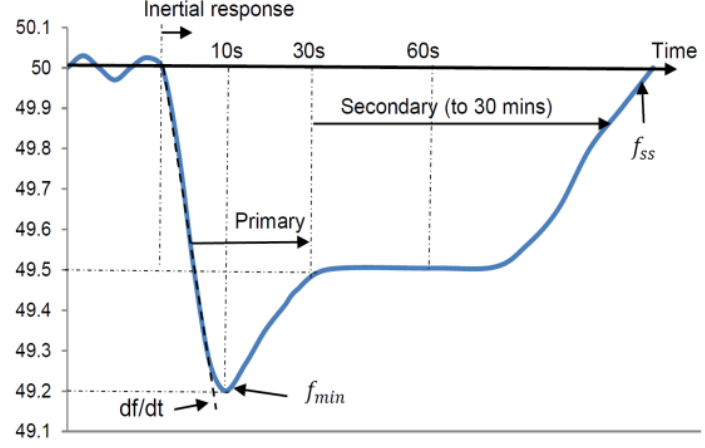

Fig. 1. Time frames of system frequency response.

The rapid increase of non-synchronous components (wind, solar, and HVDC links) on power systems makes more challenging for frequency control. Traditionally, the main functions of the conventional power plant are generating active power, controlling frequency and voltage, as well as providing rotating energy. The rotor of the synchronous generator and its turbine can provide inertia to compensate for frequency fluctuation and disturbances in short-term (inertial response at first few seconds of disturbances) since they are inherently electromagnetically coupled to the power systems. After that, the primary and secondary control take over by regulating active power through governor control with response time up to tens of seconds and minutes as shown in Fig. 1. However, most of non-synchronous generations are based on converter interface; they decouple to the system, and therefore, do not provide inertia support to the system during frequency incidents. Additionally, ancillary control services for dynamic control of conventional generator are also missing in converterbased systems. Consequently, the high penetration of converter-interfaced generation into power systems makes system inertia significantly reduced and introduces new control requirements. This leads to a faster frequency dynamic with a larger ROCOF and frequency deviation, as well as a bigger steady-state frequency error as shown in Fig. 2. A lower inertia constant results in a higher ROCOF and a larger the frequency deviation during disturbances, which does not give enough time for the primary control regulating the power output. As a result, ROCOF and frequency deviation quickly reach the threshold while primary control has not fully activated yet. This may lead to ROCOF-based protections activating to protect machines and electric equipment, which may cause sudden imbalances in generation and demand. Therefore, frequency deviation arises to an unacceptable level; the disconnection of generation like renewable generators, HVDC links, or loads is resulted in, which may cause a cascading failure or even a system collapse. 


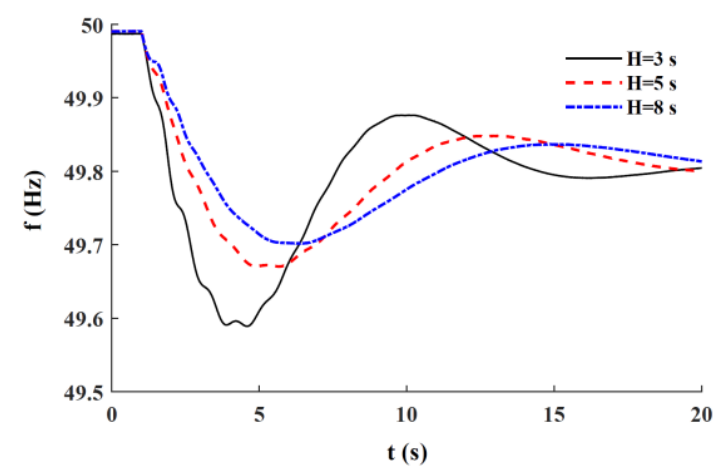

Fig. 2. System frequency response with different inertia constant.

Oscillatory instability is another issue caused in converter-based systems. Low inertia systems with a limit of short-circuit power from converter-interfaced generation may cause poor dynamic performance compared to conventional grids. Instability issues resulted from power oscillations due to low inertia operating conditions and weak interconnections among power systems are therefore more significant. The oscillatory characteristic in low inertia systems is completely different from that of conventional systems due to the different physical characteristics and interaction with the grid of converter-based components.

A power oscillation is found in a low inertia system $[13,14]$ during a small load increase where the system operated based on converter-based generation as shown in Fig. 3. Traditionally, in order to damp power oscillation, a power system stabilizer or power oscillation damping controller is designed based on the dominant oscillation mode that is determined from the state-space model of systems through finding the eigenvalues of systems. The controller parameters are designed based on that dominant mode by increasing its real part, hence moving the mode to the left side of the complex plane $[15$, 16]. However, in the converter-interfaced systems that are complex and consist of thousands of state variables, it is extremely hard to achieve their linear models. To address this issue, it requires innovative solutions for oscillation-damping controller, which adapts to the modern system characteristics to guarantee the secure operation.

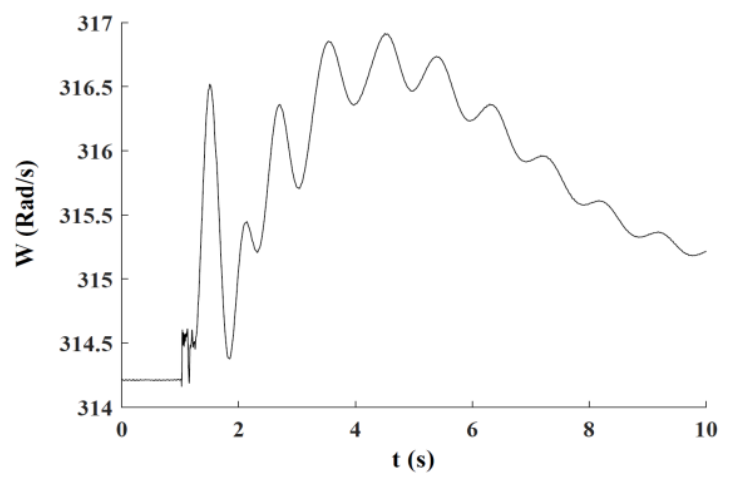

Fig. 3. Power oscillation in converter-interfaced systems.

Some countries have renewable energy sources able to cover $100 \%$ of the demand, which have faced the frequency control challenges due to low inertia conditions as follows. On 28 September 2016, the Australian power system had undergone a frequency collapse due to the presence of a high penetration of renewable energy (majority from wind power) and insufficient reserve to secure against disturbances [17]. With a combination of increasing renewable source integration and decommissioning of conventional power plants, maintaining sufficient inertia in the system to guarantee operational security is the main challenge of the Nordic power system [18]. Recently, a 1200-MW solar photovoltaic resource in the Southern California system was disconnected because of a perceived system frequency below the threshold [19]. European transmission system operators are required to study the frequency characteristic for the European system due to low inertia conditions [20]. The frequency characteristic of the interconnection system is still acceptable with reduced system inertia. However, a case of isolated operation after disturbances, the resulting power imbalances and low inertia conditions can cause a system blackout. A low inertia condition with low consumption caused an undamped oscillation event on 3 December 2017 in the continental European power system [21].

From the above-mentioned analysis, many challenges have been introduced and experienced on frequency control in low inertia systems. Researching in this area is extremely necessary to address these challenges to guarantee a smooth transition to sustainable energy systems.

\section{The potential solutions}

Recent literature review, some potential solutions have been investigated for the challenges of frequency control in converter-interfaced systems, which can be classified into two main categories: demand side and generation side. While the generation side can be applied for renewable energy sources by synthetic inertia implementation, energy storage, and synchronous condenser (SC), the demand side is used for managing the load power from the consumer's side.

\subsection{Synchronous condenser}

SC has played an important role for reactive power compensation and keeping voltage stability in power systems for more than 50 years [22, 23]. Another important benefit of the SC is short-circuit power support in the network, which can improve system stability with weak interconnections and facilitate system protection [24].

SC has been successfully applied to many grids for dynamic voltage regulation and short-circuit current support. Denmark has been successfully operating SCs, five SCs were installed at five LCC-HVDC terminals for reactive power compensation in the Danish power system [25]. Nine SCs were equipped with Hydro Quebec system for fast voltage stability enhancement [26]. In order to maintain the proper short circuit ratio at the converter station in Jeju Island, two new $13.2 \mathrm{kV},+50 /-$ 25 Mvar SCs were installed for the stability of the HVDC 
control [27]. Four SCs with $+25 /-12.5$ Mvar were installed in Vermont for low voltage ride-through issue [28]. To improve dynamic voltage regulation and support short-circuit power, one $+560 /-310$ Mvar SC converted from coal plant was implemented in Midwest of Metropolitan Area, while SC application was proposed for short-circuit current support of WPPs connected to weak AC systems [29]. Seven SCs have been installing in the California system for voltage regulation and shortcircuit support [30].

Recently, in order to deal with the impact of renewable resources on grid performance due to poor short-circuit power and low inertia support from converter-interfaced sources, SC is proposed as a potential solution for low inertia systems to support dynamic performance [31]. The benefit of SC in terms of inertial response support for frequency stability in renewable-based systems is investigated in $[32,33]$. In [34], SC is proposed as a solution to decrease under frequency load shedding and improve the system frequency response with a different number of synchronous machine scenarios.

Since SC is a rotating machine, it can provide inherently inertial response due to the electromagnetic coupling with the grid. The kinetic energy stored in its rotating mass can naturally counteract ROCOF during disturbances. Additionally, SC can also support the shortcircuit power to the network that can improve system interconnections, facilitate system protection, and enhance the operation of modern power electronics installations. As a result, $\mathrm{SC}$ is a critical solution of frequency issue in low inertia systems.

Figure 4 shows a low inertia system response during a load increase disturbance with and without SC. It can be seen clearly that with SC, the system frequency is much stronger and significantly improved, ROCOF is around $0.7 \mathrm{~Hz} / \mathrm{s}$ instead of $1.05 \mathrm{~Hz} / \mathrm{s}$ without SCs case and the ROCOF curve is much smoother than that of WO case as shown in Fig. 4(b).
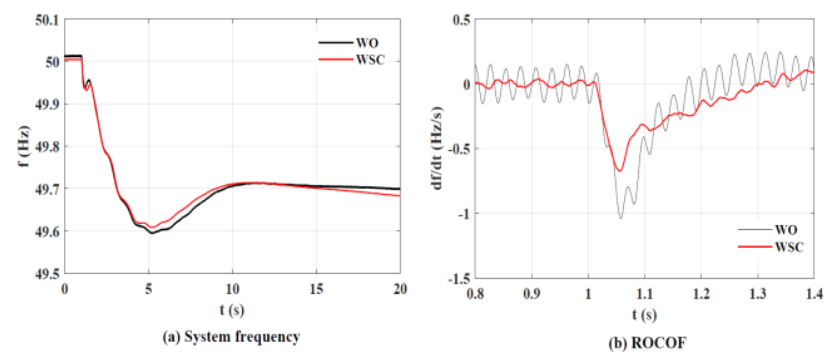

Fig. 4. System responses with and without SC.

\subsection{Synthetic inertia}

Another approach to frequency control in low inertia systems is the capacity of renewable power plants providing inertial response namely synthetic inertia (SI) for power systems, which is achieved by design a control method to regulate the power output of renewable generator during frequency excursions. Different control strategies have been proposed to apply for wind power plants (WPPs) $[35,36]$ and solar PV plants [37, 38]. In general, the basic principle of this approach is managing to accelerate or decelerate the rotor speed of WPPs to absorb or provide a temporary active power to counteract power imbalances. However, the power output of converter-based generation is limited due to power converter capacity and wind conditions.

In the literature, there are three main techniques to implement frequency support using variable speed wind power plants without any energy storage systems, namely inertial response control, droop control, and de-loading control.

Inertia emulation is implemented to extract the kinetic energy stored in rotating blades of the wind turbine, which is used to terminate the frequency change during power imbalances. Fig. 5 shows inertial emulation control, which imitates the inertial response of traditional power plants $[39,40]$.

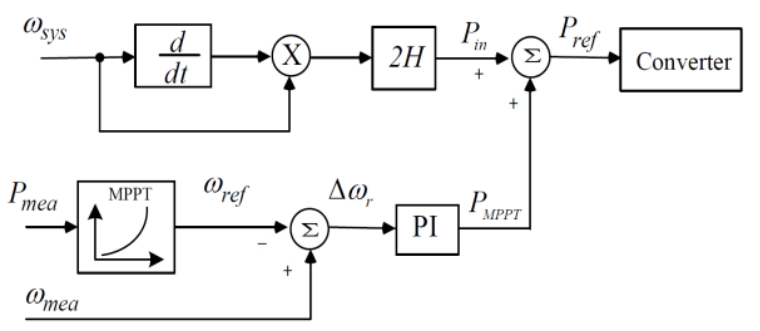

Fig. 5. Inertial emulation for WPP.

Fig. 6 shows a droop control implemented for WPPs that is proportional to the frequency deviation [41, 42]. Whenever a certain frequency deviation exists, the extra power is generated to add to the maximum power to terminate frequency excursions. This control method mainly improves the frequency deviation during disturbances.

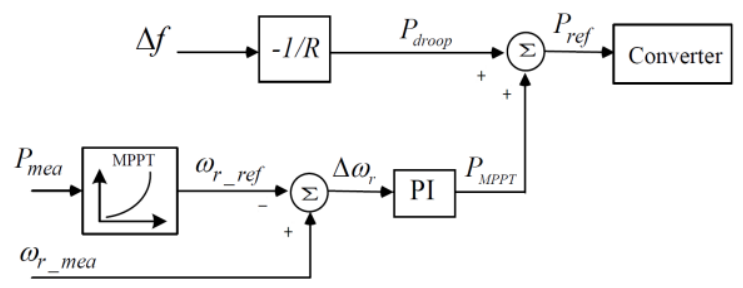

Fig. 6. Droop control for WPP.

De-loading control is the technique forced the wind turbine operating at sub-optimal power point tracking curve to ensure a reserve margin for WPPs participating in frequency control. From the aerodynamic behaviour of a wind turbine, the mechanical power extracted by the turbine is expressed as follows:

$$
P_{\mathrm{m}}=0.5 \rho A C_{\mathrm{p}}(\lambda, \beta) \mathrm{v}^{3}
$$

From equation (1), the output power of the wind turbine depends on the tip speed ratio $\lambda$ and pitch angle $\beta$, hence de-loading control can be implemented by speed control [43] or pitch angle control [44]. However, this method is not optimal regarding the economic point of view.

Power electronic converters are generally faster for providing primary control than conventional power plants. 
However, they do not respond "naturally" to power imbalances, the very first instants after disturbances might not be fully covered. As a result, this control method does not affect much ROCOF but greatly impacts on the frequency deviation [42].

Different SI control strategies are applied to a low inertia system during a load increase disturbance as shown in Fig. 7. It can be seen from Fig. 7 that the system frequency is improved when the SI controller is in service. With the $d f / d t$ control loop (red line), there is an enhancement in ROCOF from $0.27 \mathrm{~Hz} / \mathrm{s}$ to $0.21 \mathrm{~Hz} / \mathrm{s}$, but the frequency nadir is slightly lifted around $0.03 \mathrm{~Hz}$ compared to that of WO case. The much larger enhancement in the frequency nadir is obtained by the $\Delta f$ control loop and both two control loops, which increases from approximately $49.26 \mathrm{~Hz}$ to around $49.5 \mathrm{~Hz}$. With both two control loops, the frequency deviation is remarkably enhanced around $0.34 \mathrm{~Hz}$ and the frequency gradient is also improved compared to without the SI controller case as shown in Fig. 7.

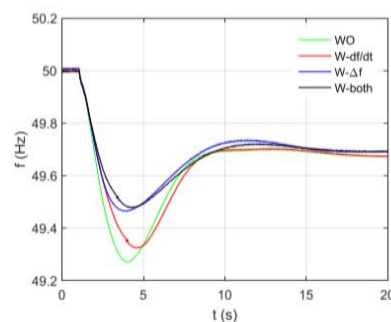

(a) System frequency

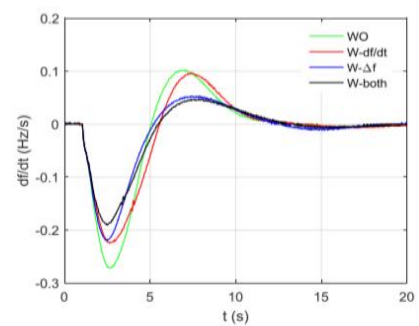

(b) ROCOF
Fig. 7. System responses during a load increase disturbance with different SI control strategies.

The combination of SC and SI which may pronounce the inertial response and a fast frequency control of a synchronous generator during power imbalances is investigated in [12]. The inertial response from SC remarkably improves ROCOF, afterwards a frequency control support with fast time response from SI of WPPs takes over and significantly enhances frequency deviation. As a result, a combination of SC and SI can not only help system frequency improve ROCOF and the frequency deviation, but also make system frequency much stronger during frequency excursions.

\subsection{Energy storage}

Energy storage is another solution for frequency support in low inertia systems. Many different types of energy storage have been developed to address the challenge of frequency control in converter-based systems such as pumped hydro storage, thermal storage, flywheel, battery, and compressed air [45, 46]. The storage can be incorporated in the frequency control services to rapidly activate for frequency control during frequency disturbances. Consequently, they can improve ROCOF and frequency deviation during disturbances. These technologies can be used for renewable energy sources, which can store power during overproduction and utilize during underproduction [47]. However, these technologies are considered expensive solutions, which need further development to use in an efficient way.

\subsection{Demand side control}

Demand-side control is a method managing the demand from consumer's side to support frequency control during disturbances. The technique usually reduces the demand to compensate for power imbalances like loss of generation, which is investigated in Great Britain [48, 49]. Demand-side control requires consumer participation and data management, and is considered as a potential solution for frequency control in low inertia systems. However, this approach has not fully developed yet, and further research will be required.

\section{Research opportunities of frequency control in low inertia systems}

Many challenges of frequency control in low inertia systems have been well recognized and experienced around the world. Furthermore, many potential solutions have been reviewed to address the challenges of frequency control in converter-interfaced systems. It is still lack of a scientific foundation for analysis, modelling, and control of low inertia systems, which can be applicable to general systems. Further research on frequency stability and control for modern power systems still needs to be done. There is some suggested future work as follows:

Coordinating SI controller with pitch control for WPPs to optimize the frequency control during overfrequency disturbances. More research would be done on the performance of SI of WPP combined with energy storage devices to supply both inertial response and primary control for frequency control during frequency excursions.

Researching on the capability of HVDC for providing inertial response and implementing control service to extract frequency control support from HVDC interconnections are necessary for low inertia systems.

Researching on demand model and implementing supplementary control for frequency control in demandside during frequency events is required for further investigation in low inertia systems.

Monitoring and forecasting system inertia to ensure stable system operation for low inertia systems. Being aware of the system inertia and kinetic energy, TSOs can actively schedule power reserves and understand good insight into the upcoming operation conditions. An online inertia estimation tool through the SCADA system has been implemented in the Nordic power system based on the breaker status of synchronous generators and their apparent power and inertia constant. However, more research in this area is necessary to propose a complete and accurate approach for low inertia systems.

Researching simulation-based approaches for determining the oscillatory characteristics in low inertia systems, which include many different components and are large-scale systems, is necessary. In the literature, the oscillatory characteristics of power systems are extracted 
based on small-signal analysis using the linear system model. This method has benefits for studying sensitivity problems and drawing general conclusions. However, the method places limits on the system model, which requires some simplifications, especially simplified control systems. As a result, the method may be inaccurate for some characteristics that have a crucial effect on the system performance during disturbances. Conversely, simulation-based approaches are less limited by the system modelling, which enables quantitative conclusions to be obtained for each particular scenario but hinders the formation of general conclusions. Therefore, more research for determining the oscillation characteristics of simulation-based approaches will help to obtain general and accurate conclusions for this simulation-based approach.

\section{Conclusion}

The dominance of converter-based generation in modern power systems renders more challenges for system frequency stability and control. This paper investigates the challenges and potential solutions of frequency control of such low inertia systems. Additionally, research opportunities for frequency stability and control in low inertia systems are analysed and recommended, which require further investigation for converterinterfaced systems.

This work is supported by Synchronous Condenser Application (SCAPP) project funded by ForskEL program, grant no. 12196 administrated by Energinet.dk [12] and Phoenix project funded by Ofgem, UK, through the Electricity Network Innovation Competition (NIC).

\section{References}

1. REN21, "Renewables Global Status Report 2015," Tech. Rep., 2012.

2. Energinet.dk, “Annual report 2015," Denmark, 2015.

3. REN21, "Renewables Global Status Report 2018," Tech. Rep., 2018.

4. Energinet.dk, "COBRAcable: interconnector to the Netherland," Denmark, 2016.

5. Energinet.dk, "Viking link: interconnector from Denmark to Great Britain," Denmark, 2016.

6. V. Sitnikov, D. Povh, and D. W. Retzmann, "Solutions for large Power System Interconnections," in Proc. for Synchronous Operation of the East-West Interconnection in Europe conference, St. Petersburg, Sep. 17-19, 2003.

7. P. Tielens and D. V. Hertem, "The relevance of inertia in power systems," Renew. Sustain. Energy Rev., vol. 55, pp. 999-1009, Mar. 2016.

8. M. Federico, D. Florian, H. Gabriela, J. H. David, and V. Gregor, "The relevance of inertia in power systems," in Proc. 20th Power Systems Computation Conference (PSCC), Dublin, Jul. 2018.

9. A. Ulbig, T. S. Borsche, and G. Andersson, "Impact of low inertia on power system stability and operation," presented at IFAC World Congress 2014, Capetown, South Africa, Dec. 2014

10. B. Parsons, M. Milligan, B. Zavadil, D. Brooks, B. Kirby, K. Dragoon, and J. Caldwell, "Grid impacts of wind power: A summary of recent studies in the United States," Wind Energy, vol. 7, pp. 87-108, 2004.

11. J. C. Smith, M. R. Milligan, E. A. DeMeo, and B. Parsons, "Utility wind integration and operating impact state of the art," IEEE Trans. Power Syst., vol. 22, no. 3, pp. 900-908, Aug. 2007.

12. Synchronous Condensers Application in Low Inertia Systems (SCAPP), 2014. [Online]. Available: http://www.scapp.dk/

13. H. T. Nguyen, G. Y. Yang, A. H. Nielsen, and P. H. Jensen, "Combination of Synchronous Condenser and Synthetic Inertia for Frequency Stability Enhancement in Low Inertia Systems," IEEE Transactions on Sustainable Energy, 2018.

14. A. Moeini and I. Kamwa, "Analytical Concepts for Reactive Power Based Primary Frequency Control in Power Systems," IEEE Transactions on Power Systems, vol. 31, no. 6, pp. 4217-4230, Nov. 2016.

15. L. Wang and M. Sa-Nguyen Thi, "Stability Enhancement of a PMSG Based Offshore Wind Farm Fed to a Multi-Machine System Through an LCC-HVDC Link," IEEE Transactions on Power Systems, vol. 28, no. 3, pp. 3327-3334, Aug. 2013.

16. Y. Pipelzadeh, N. R. Chaudhuri, B. Chaudhuri, and T. C. Green, "Coordinated Control of Offshore Wind Farm and Onshore HVDC Converter for Effective Power Oscillation Damping," IEEE Transactions on Power Systems, vol. 32, no. 3, pp. 1860-1872, May 2017.

17. AEMO, "Black system South Australia 28 September 2016," Tech. Rep., Mar. 2017.

18. Nordic TSOs, Challenges and opportunities for the Nordic power system, pp. 1-66, 2016.

19. NERC, 1200 MW fault induced solar photovoltaic resource interruption disturbance, Tech. Rep., Jun. 2017. [Online]. Available: http://www.nerc.com

20. AEMO, "Frequency stability evaluation criteria for the synchronous zone of continental Europe," Tech. Rep., Mar. 2016.

21. ENTSO-E, “Oscillation Event 03.12.2017," Mar. 2018.

22. N. Mendis, K. M. Muttaqi, and S. Perera, "Management of battery supercapacitor hybrid energy storage and synchronous condenser for isolated operation of PMSG based variable-speed wind turbine generating systems", IEEE Trans. Smart Grid, vol. 5, no. 2, pp. 944-953, Mar. 2014.

23. Siemens, "The stable way synchronous condenser solutions," 2014.

24. S. Kalsi, D. Madura, and M. Ross, "Performance of Superconductor Dynamic Synchronous Condenser on an Electric Grid," in Proc. 2005 IEEE PES 
Transmission \& Distribution Conference \& Exposition: Asia and Pacific, Dalian, 2005, pp. 1-5.

25. H. Abildgaard and Nan Qin, "Synchronous Condensers for reliable HVDC operation and bulk power transfer," in Proc. 2015 IEEE Power Energy Society General Meeting, Denver, CO, Jul. 2015, pp. $1-9$.

26. I. Kamwa, J. Beland, G. Trudel, R. Grondin, C. Lafond, and D. McNabb, "Wide-area monitoring and control at Hydro-Quebec: past, present and future," in Proc. 2006 IEEE Power Engineering Society General Meeting, Montreal, Que., Jul. 2006.

27. P. E. Marken, J. P. Skliutas, P. Y. Sung, K. S. Kim, H. M. Kim, L. H. Sailer, and R. R. Young, "New synchronous condensers for Jeju Island," in Proc. 2012 IEEE Power \& Energy Society General Meeting, San Diego, CA, Jul. 2012, pp. 1-6.

28. P. E. Marken, M. Henderson, D. LaForest, J. Skliutas, J. Roedel, and T. Campbell, "Selection of Synchronous Condenser technology for the Granite Substation," in Proc. IEEE PES T\&D 2010, New Orleans, LA, USA, Apr. 2010, pp. 1-6.

29. J. P. Skliutas, R. D. Aquila, J. M. Fogarty, R. Konopinski, P. Marken, C. Schartner, and G. Zhi, "Planning the future grid with synchronous condensers," in Proc. CIGRE US National Committee 2013 Grid of the Future Symposium, 2013.

30. H. T. Nguyen, C. Guerriero, G. Y. Yang, C. J. Boltonand, T. Rahman, and P. H. Jensen, "Talega synCon - Power grid support for renewable based systems," in Proc. the Western Protective Relay Conference 2018, Washington, USA, Oct. 15-18, 2018, pp. 1-6.

31. M. Nedd, C. Booth, and K. Bell, "Potential solutions to the challenges of low inertia power systems with a case study concerning synchronous condensers," in Proc. 2017 52nd International Universities Power Engineering Conference (UPEC), Heraklion, Aug. 2017, pp. 1-6.

32. H. Zhang, J. P. Hasler, N. Johansson, L. ngquist, and H. P. Nee, "Frequency response improvement with synchronous condenser and power electronics converters," in Proc. 2017 IEEE 3rd International Future Energy Electronics Conference and ECCE Asia (IFEEC 2017-ECCE Asia), Kaohsiung, Jun. 2017, pp. 1002-1007.

33. H. T. Nguyen, G. Y. Yang, A. H. Nielsen, and P. H. Jensen, "Frequency stability improvement of low inertia systems using synchronous condensers," in Proc. 2016 IEEE International Conference on Smart Grid Communications (SmartGridComm), Sydney, NSW, Nov. 2016, pp. 650- 655.

34. Nahid-Al-Masood, R. Yan, T. K. Saha, and N. Modi, "Frequency response and its enhancement using synchronous condensers in presence of high wind penetration," in Proc. 2015 IEEE Power \& Energy Society General Meeting, Denver, CO, Jul. 2015, pp. $1-5$.
35. M. Kayiki and J. V. Milanovi, "Dynamic contribution of DFIG-based wind plants to system frequency disturbances," IEEE Trans. Power Syst., vol. 24, no. 2, pp. 859867, May 2009.

36. J. V. D. Vyver, J. D. M. D. Kooning, B. Meersman, L. Vandevelde, and T. L. Vandoorn, "Droop control as an alternative inertial response strategy for the synthetic inertia on wind turbines," IEEE Trans. Power Syst., vol. 31, no. 2, pp. 1129-1138, Mar. 2016.

37. D. Pullaguram, S. Mishra, and N. Senroy, "Modeling and design of virtual inertia based rooftop PV," in Proc. 2018 IEEMA Engineer Infinite Conference (eTechNxT), New Delhi, 2018, pp. 1-6.

38. A. Hosseinipour and H. Hojabri, "Virtual inertia control of PV systems for dynamic performance and damping enhancement of DC microgrids with constant power loads," IET Renewable Power Generation, vol. 12, no. 4, pp. 430-438, Mar. 2018.

39. F. Gonzalez-Longatt, E. Chikuni, and E. Rashayi, "Effects of the Synthetic Inertia from wind power on the total system inertia after a frequency disturbance," in Proc. 2013 IEEE International Conference on Industrial Technology (ICIT), Cape Town, 2013, pp. 826-832.

40. J. Ekanayake and N. Jenkins, "Comparison of the response of doubly fed and fixed-speed induction generator wind turbines to changes in network frequency," IEEE Transactions on Energy Conversion, vol. 19, no. 4, pp. 800-802, Dec. 2004.

41. J. F. Conroy and R. Watson, "Frequency Response Capability of Full Converter Wind Turbine Generators in Comparison to Conventional Generation," IEEE Transactions on Power Systems, vol. 23, no. 2, pp. 649-656, May 2008.

42. M. Kayikci and J. V. Milanovic, "Dynamic Contribution of DFIG-Based Wind Plants to System Frequency Disturbances," IEEE Trans. Power Syst., vol. 24, no. 2, pp. 859-867, May 2009.

43. E. Loukarakis, I. Margaris, and P. Moutis, "Frequency control support and participation methods provided by wind generation," in Proc. 2009 IEEE Electrical Power Energy Conference (EPEC), Montreal, QC, 2009, pp. 1-6.

44. P. Moutis, E. Loukarakis, S. Papathanasiou, and N. D. Hatziargyriou, "Primary load-frequency control from pitch-controlled wind turbines," in Proc. 2009 IEEE Bucharest PowerTech, Bucharest, 2009, pp. 17.

45. P. F. Ribeiro, B. K. Johnson, M. L. Crow, A. Arsoy, and Y. Liu, "Energy storage systems for advanced power applications," Proceedings of the IEEE, vol. 89, no. 12, pp. 1744-1756, Dec. 2001.

46. D. Bazargan, S. Filizadeh, and A. M. Gole, "Stability Analysis of Converter-Connected Battery Energy Storage Systems in the Grid," IEEE Transactions on Sustainable Energy, vol. 5, no. 4, pp. 1204-1212, Oct. 2014. 
47. J. Zeng, B. Zhang, C. Mao, and Y. Wang, "Use of Battery Energy Storage System to Improve the Power Quality and Stability of Wind Farms," in Proc. 2006 International Conference on Power System Technology, Chongqing, Oct. 2006, pp. 1-6.

48. A. Saffarian and M. Sanaye-Pasand, "Enhancement of Power System Stability Using Adaptive
Combinational Load Shedding Methods," IEEE Transactions on Power Systems, vol. 26, no. 3, pp. 1010-1020, Aug. 2011.

49. P. Ajay-D-Vimal and R. M. Sudhakaran, "Optimal load shedding in power system strategies with voltage stability indicators," Engineering, vol. 2, no. 1, pp. 12 - 21, 2010. 